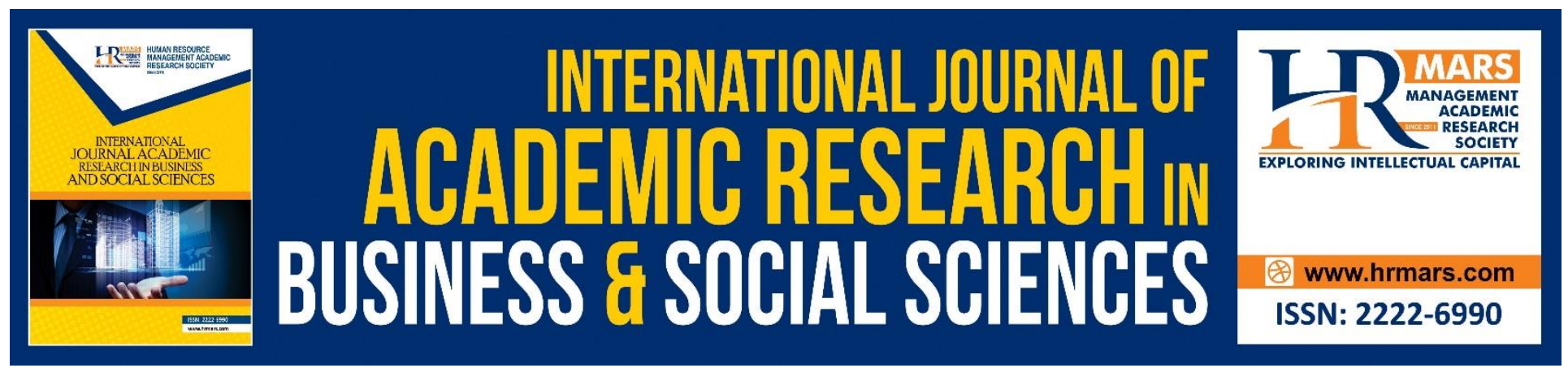

\title{
Migration Dynamics: Are Independent and Voluntary Migrants in Malaysia \& Canada Successful at Different Levels?
}

Mpawenimana Abdallah Saidi, Monisha Priyaa Balasuframaniam, Adam Andani Mohammed, Ahamad Faosiy Ogunbado

To Link this Article: http://dx.doi.org/10.6007/IJARBSS/v11-i14/8949 DOI:10.6007/IJARBSS/v11-i14/8949

Received: 17 January 2021, Revised: 20 February 2021, Accepted: 19 March 2021

Published Online: 28 March 2021

In-Text Citation: (Saidi et al., 2021)

To Cite this Article: Saidi, M. A., Balasuframaniam, M. P., Mohammed, A. A., \& Ogunbado, A. F. (2021). Migration Dynamics: Are Independent and Voluntary Migrants in Malaysia \& Canada Successful at Different Levels? International Journal of Academic Research in Business and Social Sciences, 11(14), 404-416.

Copyright: (C) 2021 The Author(s)

Published by Human Resource Management Academic Research Society (www.hrmars.com)

This article is published under the Creative Commons Attribution (CC BY 4.0) license. Anyone may reproduce, distribute, translate and create derivative works of this article (for both commercial and non-commercial purposes), subject to full attribution to the original publication and authors. The full terms of this license may be seen

at: http://creativecommons.org/licences/by/4.0/legalcode

Special Issue: Contemporary Business and Humanities Landscape Towards Sustainability, 2021, Pg. 404 - 416 http://hrmars.com/index.php/pages/detail/IJARBSS JOURNAL HOMEPAGE

Full Terms \& Conditions of access and use can be found at http://hrmars.com/index.php/pages/detail/publication-ethics 


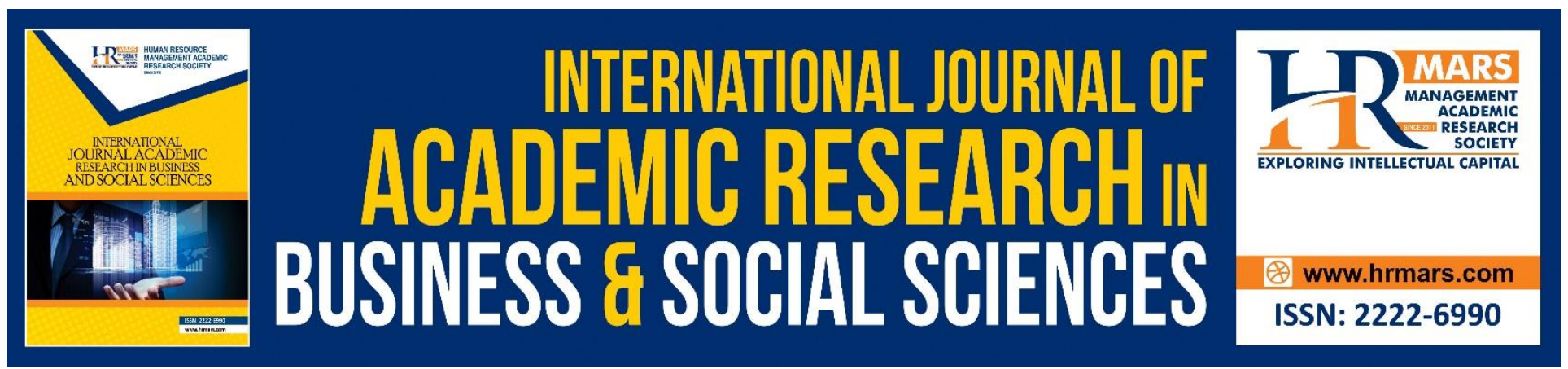

\title{
Migration Dynamics: Are Independent and Voluntary Migrants in Malaysia \& Canada Successful at Different Levels?
}

\section{Mpawenimana Abdallah Saidi, Monisha Priyaa Balasuframaniam, Adam Andani Mohammed}

Faculty of Social Sciences and Humanities, Universiti Malaysia Sarawak, Kota Samarahan, Sarawak Email: asmpawenimana@unimas.my

\section{Ahamad Faosiy Ogunbado}

(UNISSA), Brunei Darussalam

\begin{abstract}
This paper emphasizes the contemporary transnational migration happening in Kuala Lumpur (Malaysia) and Quebec (Canada), demonstrating how social living of individuals migrating either to Kuala Lumpur or to Quebec due to high skilled jobs offers and marital reasons, impacting policy implementations in the country. This paper also explains the perspectives that influences relationship between the natives and immigrants. On the other hand, states take up immigration issues for reasons of political legitimacy to reassert their stance as guardians of their national boundaries by disallowing dual citizenship in some nations such as Malaysia. Thus, a comparative analysis has been made between Kuala Lumpur and Quebec to encounter the causes and factors by questioning the social cohesion and acceptance of diversity in both locations through questionnaire and desktop research respectively. This paper briefed that the current contemporary migration is also indirectly adding up consciousness towards environmental safety and job opportunities in new emerging sectors. The immigration phenomenon in Kuala Lumpur saying that the demand for high skilled immigrants within the country directing new norms and cultural adaptation. A similar situation has been recorded in Quebec, where immigrants are viewed as a non-resistance to economic integration and community building under conditions set by Quebec policy. Therefore, this paper will be analyzing on the circumstances in Malaysia and Canada that increasing several migrants' tendency with no evidence of impact on the countries' present societal cohesion.
\end{abstract}

Keywords: Migration, Integration, Inter-Marriages, Malaysia, Quebec

\section{Introduction}

In this paper, immigration phenomenon in Canada has been set as a controlled variable to compare and relate concurrently happening transnational issues in Malaysia, where Quebec and Kuala Lumpur 
were chosen as pilot locations for this study. Societal cohesion means the willingness of a society at large to cooperate and tolerate each other for survival and prosperity. People usually emigrate to places that share almost similar historical, political and economic connections between countries. For example, Ramasamy (2006) stated that the contemporary migrants often flee between countries with economic bondage like France and Algeria, or England and India, Germany and Turkey or the United States of America and Mexico, Cuba and Central America. In this case, Malaysia shares a friendly and peaceful territorial integrity among Association of South East Asia Nation (ASEAN), Organization of Islamic Congress (OIC), G77, Commonwealth members that encourages transnational migrations to occur as a manner of trust and respect over mutual understanding they hold on Malaysia. The media lens plays an important role manipulating citizens' perceptions. One of the examples is decentralised movement advocating for non-violent civil disobedience towards Japanese-Brazilians (Asami, 2016). Almost identical subject encounter, where it is assumed that there is a chance of future territorial separatism in Malaysia. Both national and social threats complicate how we understand nation, citizenship and identity today is that in nations that have only recently begun to experience immigration, the problem that bounds across the nation conceived in "racial" terms come into conflict with the problem of incorporating visibly different immigrants.

\section{Methodology}

Correlational design applied throughout this paper as case-control study and observational study, relating variables in a predictable pattern for one group of individuals to conduct correlational research confirms non-intervention research. The study configuration is set prior to the key stage of data collection, as this paper is theory driven. Cohort study is used in this paper as the research questions and objectives indicate a strong association between cause and effect. Confirmatory research tests hypotheses in prior measurement by predicting the outcome of this paper that is to ensure transnational migration is neutralize the societal cohesion in Malaysia (by setting Kuala Lumpur as the pilot location) in the upcoming years by referring Quebec as the sample model. Brown (2015) stated that the confirmation research was applied to minimise the likelihood of falsely reporting an ideally striving coincident. In other words, questionnaires are distributed in person to the sample size population through snowballing to understand the challenges and experiences of migrants who resides in Kuala Lumpur as matter of either marital reason or acquaintance of high skilled job, and the findings from this generalizes the entire skilled migrants and marriage migrants population in Malaysia. Depth analysis case study conducted in this paper to generate a substantial amount of transnational migration data from multiple sources (Gall et al., 2007). Besides that, it is necessary to systematically coordinate migration data in Malaysia and Quebec to prevent the researcher from being overwhelmed by the amount of data and to prevent the researcher from losing sight of the original research goals and questions.

\section{Literature Review}

Most of the reviewed articles tend to stress on the global migration patterns that reflect the critical circumstances of the time due to various catalysts for migration such as regional conflicts, famine, adverse effects of climate change, unstable government and limited opportunities. Over the period, the contemporary migrations have increased with the same exact intensity, but adding up mass movement towards safety and opportunity as facilities evolves. 


\section{Contemporary Immigration in Malaysia and Quebec}

In Malaysia, migrants are immigrated through four main categories, such as family reunification, strongly linked to Malaysian residents, economic migrants and humanitarian reasons. The classification of categories is further briefed in finding analysis.

Meanwhile, Quebec is the populated province in Canada after Ontario and is at the centre of Francophone or better known as the French-speaking societies in North America. Quebec culture is a touchstone of a distinct outlook. Quebec blends its historical roots with cultural heritage and the accomplishments of recent immigrants, whilst still being deeply influenced by or recognised as an English-speaking North America. As in most Canadian provinces, the Quebec government has prioritised immigrant newcomers as a prospective asset for remote regions in the province that are encountering a population decline due to a shortage of targeted categories of jobs and an ageing population. Hanley (2017) argued that although the city faces reduction of new residents, the province remains far beyond its goal of attracting 21 percent of recent immigrants, as reported in 2005-2015, to reside out of Montreal. As a result, many small rural-town communities in Quebec today have come to rely on temporary foreign workers as workforce in certain industries.

In the last 10 years, the rate of unemployment for immigrants has almost doubled $11.2 \%$ for those born in Canada by $5.8 \%$. In addition, 43 per cent of immigrants are over-qualified for their positions, compared with $29.7 \%$ of Quebecers over-qualified Cosca (2016) included in his report a new Montreal consulting group report that new arrivals in Quebec are experiencing massive unemployment and lower earnings, as most of them are more excessively-qualified for their job vacancies than other Quebecers. Thus, the application that accepts through immigration portal for every period annually has set limited positions while tackling this issue.

\section{Findings and Analysis}

The meaning of the impacts of immigration and community stability are associated with social networks, community divisions and intergenerational disparities evaluations. The analysis is made upon the personal interviews and online surveys collected from individuals with residential status as permanent residents and temporary residents with stay permit flexibilities. 


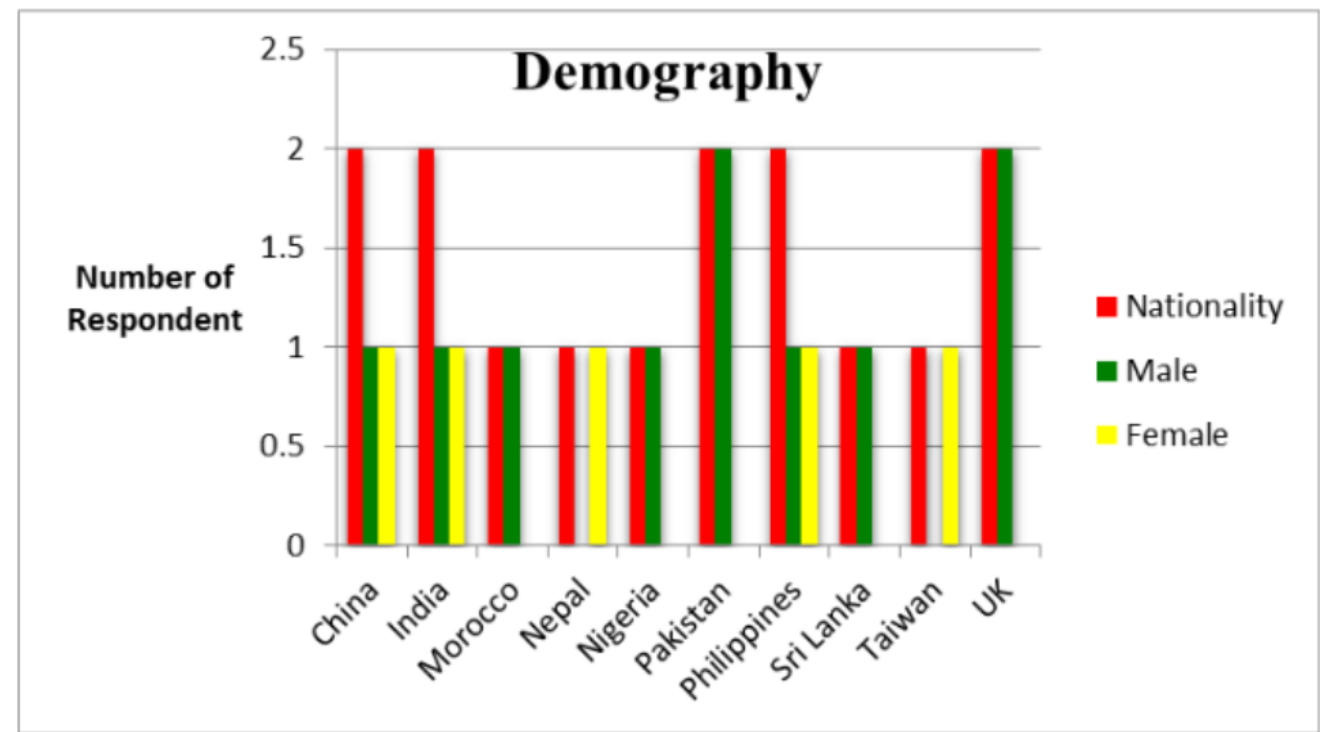

Chart 1: Number of Respondent as based on Nationality and Gender Identification

Chart 1 portrays 66.7 percent of the population is male respondents while about one over three is female respondents. Interviewees from various continents of the world such as Asia, Africa and Europe were invited to participate in the survey to ensure impartiality in the essay statement. Out of 15, China, India, Pakistan, Philippines and the UK each have two responders than immigrants from other nations, while less than 5 percent of them reported that hardly find their home country representative commission in Malaysia. According to MIDA (2013), skilled migrants in Malaysia are categorised into few segments in the tertiary or service industries. The Malaysian government has developed a framework for the New Economic Model to move the country from a middle-income to a high-income economy premised on innovation, creativity and high-value supply market. Within this model, initiatives to attract more skilled immigrants for economic maturity have been stepped up to target industries in which Malaysia has solid fundamentals for new emerging areas. Indeed, there is a plethora of methods in which the sector, the third parties, the firms and the types of jobs within them can be identified. Similarly, one third of the respondents are entrepreneurs and owning private limited companies in Kuala Lumpur, whereby the remaining 70 per cent are from engineering base and teaching sectors. Yet the similarities between the immigrants are all of them involved in tertiary sectors and more than half of the sample population married to Malaysian. 

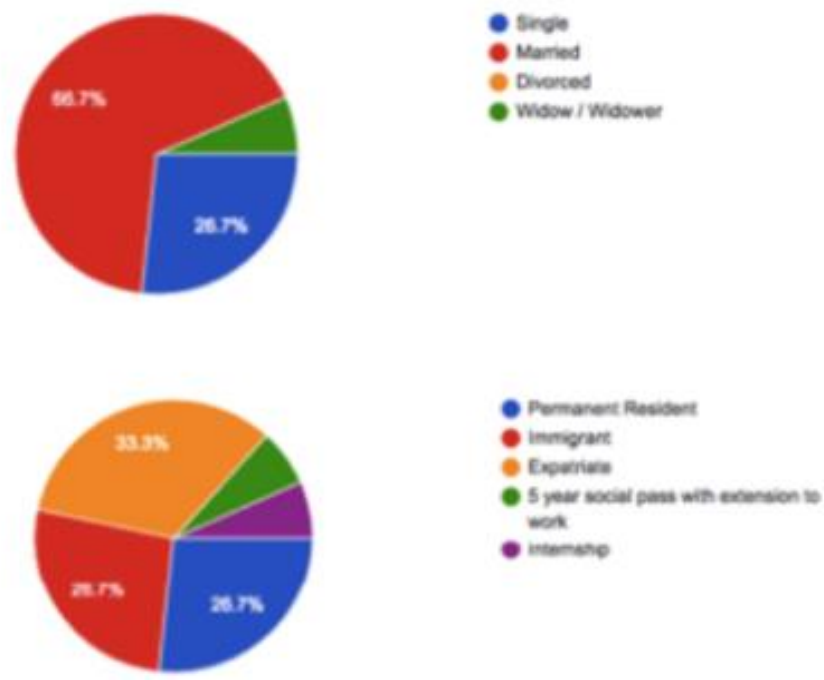

Chart 2: Percentage of Marital and Residential Status of Respondent

Chart 2 indicates the marital status of the 15 respondents that live in Kuala Lumpur. Most interviewees were expatriates and have no intention to apply for Malaysian citizenship due to the prohibition of dual citizenship conditions in Malaysia. Another reason is because they would like to leave the options wide to their children to choose citizenship either to remain as Malaysian or apply for parent's home country once they reach the age of 16 . Apart from that, more than 40 per cent of them said they might return to their home country or migrate to a third country in future. Thus, they find no rush to apply for permanent residence-ship yet, unlike the remaining 33 per cent of marital reason. Both surveys have notified that more than half of the expatriate sample population in Kuala Lumpur are trying to learn and utilise the local language, despite its difficulty in adaptation. Besides, nearly one-third of participants said they were travelling more since embarking life as an expatriate to embrace the sense of adventure, while more than half of the respondents described Malaysia as a culturally diverse and interesting place to set as home.

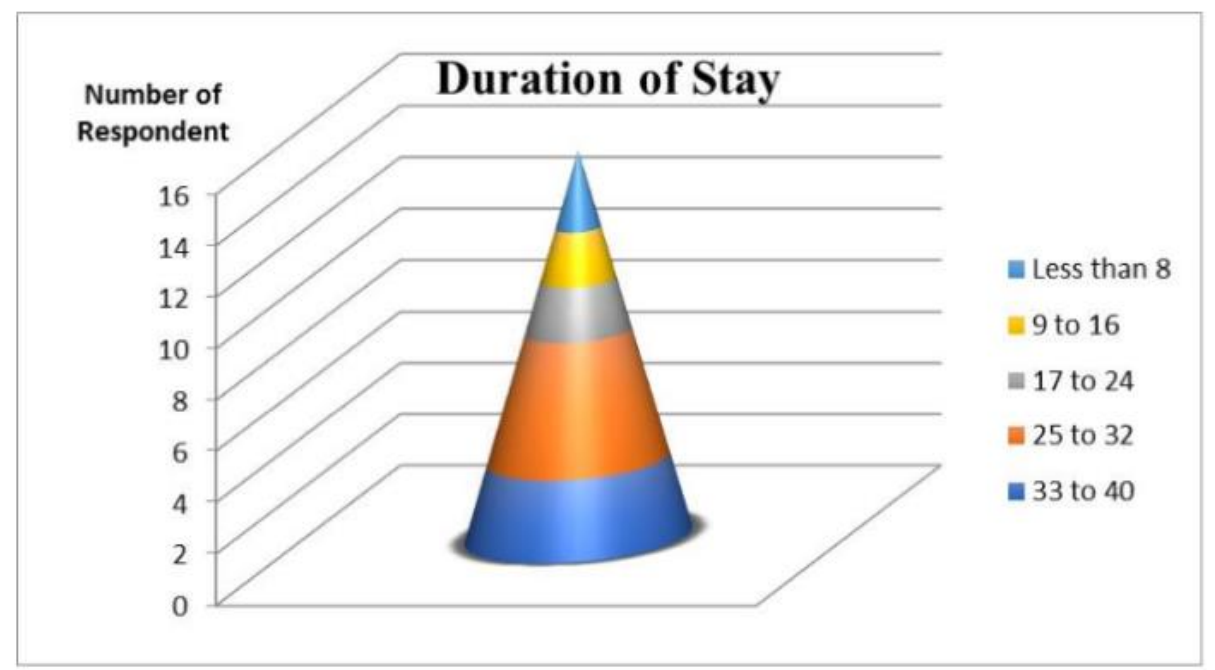

Chart 3: Percentage on Respondent's Duration of Stay in Malaysia 
The third chart above presents the staying duration of every respondent in Malaysia. The interviewees have selected the range between 25 to 32 years the most whereas almost 15 percent of them just migrated in less than 8 years ago. A significant difference in the perception they have on Malaysia is partially influenced by their residing period in the country. The longer the living experience, the more they compare the facilities and infrastructures to developed nations. Most of them admitted that Malaysia is a peaceful and friendly state that encourages diversity and development. However, almost half of them felt the concern on preserving traditional values and environmental awareness is quite lacking. Thus, this demonstrates that social cohesion between immigrant and local is well versed but way of seeing a common issue is different such as on pollution, political awareness, and economic concern. The Malaysians' nationalism was expressed as fragmented by the 15 volunteers. Some felt that the major differences exist in the thinking style between the cities and the more rural communities and there is little evidence of unity when externally challenged. For example, unity was observed when Malaysian authentic dish "chicken rendang" was criticised and the nation's effort to restore democracy in the recent general election. Yet, the unity bond to work as a nation between rural and cities was yet to be achieved. This is because the cosmopolitan affects the western culture addiction whereby the countryside relies more on the mass media to contribute information about the state's well-being. Nearly most religions are freely practised in the country with no objections as per stated in the constitution. Almost all of the team mentioned were speaking English and their mother tongue language in the family. The volunteers also demonstrate that their current lifestyle has at least slightly impacted the Malaysian culture such as in food adaptation, common language usage (Malay), working timing, and way of thinking. Two-third of them believe the nation will be more independent in the way carrying perspectives and social values will be taken into consideration in the process of modernisation.

Causes and Factors of Societal Cohesion in Quebec

Driven by social contract theory developed through multiple perspectives by John Locke, Thomas Hobbes and Jean Rousseau, all of them mentioned that an agreement made on mutual consent to achieve personal interest without violating the nature of state and to maintain social equality. The Quebec economy is generally one-fifth of Canada's total GDP. Like most industrialised nations, Quebec's economy is primarily premised on the services sector, analogous to Hong Kong. Traditionally, Quebec's economy has been fueled by plentiful resources, excellently-developed infrastructure, and annual production. Quebec is experiencing faster growth of its research and development spending than other Canadian provinces (Statistics Canada, 2017). 


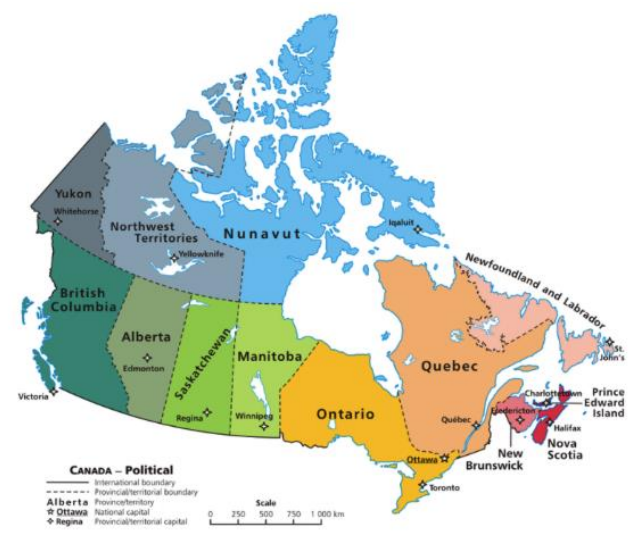

Source: Google Image, 2018

Image 3: Map of Canada

Image 3 illustrates the political state division of Canada, where Quebec is the eastern part of the country prominently recognised as the cities with fault line. Regions situated where two or more ethno-cultural, economic or geopolitical realms intersect, where this situation may, within certain circumstances, be demonstrated via intensified conflict, violence or open warfare. As a result, a few fault-line cities are regarded as disputed, scattered or perhaps divided walls, drawbridges and ethnocentric asphalts, just like Nicosia or Jerusalem (Wilczewska \& Greta, 2017). The adaptation of rationalism as ascribed by Max Weber also shows tremendous changes in the migration process that occur in Quebec over the decades. Some analyses are done on modern society, whether earned migration is part of solidarity or individualism apart from the role of traditional society or migrating culture kinship as nomads. Durkheim briefed that, by resemblance with coherence, the aspects of raw materials are linked together, in contrast to one that embodies the wholeness of living creatures (Gofman, 2014). Thus, explains that cohesion among a group of people will occur when the individuals share something in common.

\section{Internal Structures on Human Development}

Growing optimistic generation in Canada has no objection to the state decision to implement open door policy for skilled migrants is another strength of the unification policy for national development. However, through this study, the acceptance level of Malaysian towards open door policy remain vague as the scenario have the tendency to confine job opportunities and wage scale for native in future. Therefore, implementation and upgradation of immigration policy in Quebec synthesized in this paper in order to highlight the advantages and potential breakdowns to localise the policies to Malaysian context.

According to the Human Development Index set by the UN, there are six basic pillars stresses on people centric approaches: equity, sustainability, productivity, empowerment, cooperation and security. By taking all the statements mentioned above, the Quebec government measures the Human Development Index as the remedial program for racial integration so that social cohesion is well taken care of equally as the locals. In addition, Quebec is a fair and independent society that ensures national unity as a key component of a state policy that respects the legal system. Quebec social system centers its cohesion and thoroughness on a series of attributes, including the "Quebec 
Charter of Human Rights and Freedoms," the "Charter of the French" and the "Civil Code of Quebec." A large proportion of new members to Quebec are analysed through several province's famed economic migration channels. Program of qualified workers of Quebec (QSWP), Quebec experience program, and Quebec business program are being offered under the economic streams. Moreover, prospective immigrants will be eligible to apply for Canadian permanent residency through Quebec Selection Certificate (CSQ). The certificate is actually used to evaluate the total scored points to a selection grid of factors via online application.

\section{Quebec Immigration Admission Targets 2018}

\begin{tabular}{|c|c|c|}
\hline Category & Minimum & Maximum \\
\hline Economic immigration & 28,700 & 31,300 \\
\hline - Skilled worker & 24,200 & 26,300 \\
\hline - Business & 4,000 & 4,300 \\
\hline - Other economic* & 500 & 700 \\
\hline Family reunification & 11,600 & 12,100 \\
\hline Refugees and people in similar situations & 8,100 & 8,800 \\
\hline - Refugees selected abroad & 5,600 & 6,000 \\
\hline 1. State-funded refugees & 1,550 & 1,600 \\
\hline 2. Privately sponsored refugees & 4,050 & 4,400 \\
\hline - Refugees recognized locally & 2,500 & 2,800 \\
\hline Other immigrants** & 600 & 800 \\
\hline Total & 49,000 & 53,000 \\
\hline
\end{tabular}

Source: The Quebec Immigration Board, 2018 Diagram 1: The Present Immigrant Admission Target

The above briefs on the annual target set by the ministry to receive more immigrants under opendoor policy. More allocation of admission was structured to economic immigration than family reunification and refugees. A general reason behind the classification of the type of migrants is to analyze the potential of better economic flow in the country apart from ensuring the national security of the nation. Individuals that would not fall under any categories but part of humanitarian policy is classified as the other immigrants and given the least admission quota. Quebec attracts more French speaking and French cultured people to immigrate as it eases the communication facilities with the locals. Nevertheless, out of the maximum target application, less than 25 per cent will be selected by 
the Quebec immigration.

The overwhelming invitation from the Quebec Immigration eventually resulted in the rise of immigration forgery over the few years. Some of the famous frauds found more often are marriage fraud, document fraud, irregular adoption and telecommunication scam. The cases of locals married to immigrants to gain special privilege and permanent residence is the most common issue in the country. The locals were said to be convinced to be paid and married to foreigners for a shorter period of time until status approval resulted from the immigration commission. Nevertheless, the document fraud and telecommunication fraud are encountered to be cheated by third parties or by the scammers (Government of Canada, 2018).

\section{Discussion}

Community cohesion is defined as the propensity of a group of folks to work together to continue to survive. Stanley (2003) briefed that the readiness to collaborate means that it is appropriate for them to choose to build alliances freely and have a sensible chance of achieving goals or objectives as others willingness to give the berries of their efforts fairly. In fact, the UN has recently integrated this notion in the new Sustainable Development Goals in 2015, stressing on issuing policies that unify all segments of society quickly is critical in achieving target measures by 2030 . The policies avert and overturn the exclusion of immigrants to foster positive ties with the local community. Moreover, the strategies implemented encourage social accessibility for immigrants by enhancing labour force mobility, enabling entrepreneurship and education availability. Besides, OECD (2011) agreed that providing migrants with the proper space to voice their concerns is essential to sustainable development and compassionate society. The equipment of civic participation evaluation framework is essential for positive and continuous growth. This is notably evident in the case of transitioning wealth, which accelerates social dislocation and economic growth that calls for innovative reactions: the policy-making process for building social cohesion.

The core-periphery model, which was initially created by Frank as the sign of development in both North and South nations especially during the colonization period that led to imperialism, which has widened the obvious gap of wealth between developed and developing countries. Moreover, the dependency model has also created peripheral divisions within nations like Malaysia. For instance, a high number of inward migrations is being noticed annually in Kuala Lumpur, better known as the core centre of industrialization in Malaysia due to rapid technology and capital developments, requiring a high number of manpower. Thus, this formed the concentration of both white- and bluecollar laborers from abroad and within. However, as a result of unequal economic distribution between the cities and sub towns, a possible collapse of indigenous culture and inherited business were found in most outskirt areas in Malaysia (Nokman, 2017).

The mobility also encouraged territorial division while the nation was working on economic development, which eventually intensified ethnic cleavages in the country. Diagnosis of exclusion increases ethnic awareness and responsiveness to ethnic nationalist appeals (Richardson Jr. \& Shinjinee, 1996). Rapid industrialisation is widely assumed to be the catalyst for economic growth, and the benefits of economic growth will be widely disseminated, resulting in public welfare improvements. Thus, the massive flow of inward economic migration created the locals to hold job 
insecurity and unemployment as the competition for job seeking rises. Although the success of decolonization brought sovereignty and liberty, it still brought obstacles to national unity in most colonies. For example, the "Modern Africa is the product of Europe". The similar situation encountered in Malaysia under the colonial policy, to divide and rule that resulted to ethnic fragmentation among the Malaysian that share diverse originality, language and customary lifestyles. Despite this, national unity was upheld through assimilations and inter-racial marriages. The nation has practiced and gotten used to the salad bowl culture even before reaching the post-independence era. For instance, the culture of giving angpao during any festival in Malaysia, although initially the custom was part of Chinese community (ASEAN, 2007). Thus, this clearly explains the policy solely does not strengthen the national unity but the culture of acceptance and learning made the manifold community unified.

Wolff (2006) mentioned that "either in ethnic conflicts are extremely diverse, ranging from legitimate political, social, cultural, and economic grievances of disadvantaged ethnic groups to predatory agendas of states and small cartels zof elites, or to so-called national security interests". Malaysia is one of the countries that has avoided large disparities in regional investment, such as Singapore and Tanzania. Malaysia is taking steps to reduce regional imbalances, in particular the privilege policies for the Bumiputera have excelled in building a pool of trained and educated Malays who would lead regional integration in order to reduce ethnic tension between the majority and the rest (Richardson Jr. \& Shinjine 231996). The 1Malaysia program was introduced in 2010 as part of the socio-economic policy, with a strong emphasis on tribal harmony, nationhood and proactive governance in the country.

The very first election of Persekutuan Tanah Melayu (Malaya) on 27 July 1955 before the formation of Malaysia nation state drew political excitement among the multi-racial society. The campaigns in the progress to achieve independence also showcased innocence and tolerance capabilities with an agreement of establishing ethnic politics in the nation as based on quota allocation for equal justice and orders for every individual in the state without neglecting cultural variations. Apart from that, the Malay community which initially recognized as the locals during the British colonization agreed to accept the immigrants brought by the British from various colonies majorly from China and India to be given citizenship if suits the criteria of being a Malaysian. Whereby, the special privileges that were given to the Malays or better known as the Bumiputera shall be obeyed and accepted by the communities.

\section{Conclusion}

This paper therefore validates the occurrences in pilot locations, Kuala Lumpur and Quebec are rising the propensity of number of migrants without any proof of effect on the existing social stability of the Malaysia and Canada respectively. The immigration trend in Kuala Lumpur has shown that the high demand for skilled immigrants is driving new norms and cultural adaptation. This perpetuates local community are expressing acceptance and respect towards migrants within neighborhood. A similar approach has been observed in Quebec, where immigrants are perceived as principle of not resisting authority to economic cooperation and civic engagement under the guidelines set out in their policy. 
Despite the similarities, national and social threats complicate our understanding of nation, citizenship and identity. The problem that crosses the country conceived in "racial" terms, is in conflict with the problem integrating with immigrants with unfamiliar cultural background. Almost identical subject encountered, where it is assumed that there is a chance of future territorial separatism if peaceful co-existence and mutual benefit in relations are neglected. Although freedom of migration is unavoidable but still controllable by implementing some requirements and limitations, through continuous monitoring and evaluation with the principles of engagement and cooperation between natives and migrants needs.

\section{References}

Asami, Y. (2016). Overview of the Evolution of Social Security in Asian Countries. Comparative Politics, Hitotsubashi University.

ASEAN. (2007). ASEAN Consensus on The Protection and Promotion of the Rights of Migrant Workers. ASEAN Coordinating Council, ASEAN Summit. Cebu: ASEAN Community.

Bali, S. (2008). POPULATION MOVEMENTS. In P. D. Williams, SECURITY STUDIES: AN INTRODUCTION (pp. 468-480). UK: Taylor \& Francis e-Library.

Bouchon, F. A. L. (2014). Truly Asia and global city? Branding strategies and contested identities in Kuala Lumpur. Place Branding and Public Diplomacy, 10(1), 6-18. https://doi.org/10.1057/pb.2013.21

Canadian Citizenship \& Immigration Resource Center. (2018). Immigration.ca. Retrieved March 18, 2018, from Quebec Immigration Categories: http://www.immigration.ca/quebec welcomenear-53000-immigrants-2018/

Fischer, M. L. (2013). On Social Equality and Difference, a View from The Netherlands. Management Education and Development, 16(2), 201-210. https://doi.org/10.1177/135050768501600217

Gofman A. (2014). Durkheim's Theory of Social Solidarity and Social Rules. In: Jeffries V. (eds) The Palgrave Handbook of Altruism, Morality, and Social Solidarity. Palgrave Macmillan, New York. https://doi.org/10.1057/9781137391865_3

Government of Canada. (2018). Immigration and Citizenship. Retrieved March 18, 2018, from Protect

Yourself from Fraud: https://www.canada.ca/en/immigration-refugees-citizenship/services/protectfraud/html?utm_source=slash-immigration-fraud_fraude-immigration\&utm_medium=shorturl-en\&utm_campaign=antifraud

Habibu, S. (2017). Renounce or risk revocation, dual citizenship holders told. The Star Online. https://www.thestar.com.my/news/nation/2017/01/31/renounce-or-risk-revocation-dualcitizenship-holders-told/

International Organization for Migration. (2011). Glossary on Migration, International Migration Law Series No. 25. Retrieved December 1, 2017, from The UN Migration Agency: http://www.iom.int/key-migration-terms

Kamaruddin, S. B. (2014). UKM Portal. Retrieved October 10, 2017, from Malaysia Close To having Social Cohesion, Says Prof Shamsul Amri: http://www.ukm.my/news/archieve/tahun2014/january 2014/malaysia-close-to having-social-cohesion-says-prof-shamsul-amri/

Ministry of Education Malaysia. (2012). National Education Blueprint 2013 -2025. Retrieved February 14, 2018, from https://www.moe.gov.my/images/dasar-kpm/PPP/Preliminary-BlueprintEng.pdf

Nokman, F. S. (2017). More than 150,000 UNHCR registered refugees, asylum seekers in Malaysia. 
New Straits Times. https://www.nst.com.my/news/nation/2017/07/260905/more-150000unhcr-registered-refugees-asylum-seekers-malaysia

OECD (2011). Perspectives on Global Development 2012: Social Cohesion in a Shifting World, OECD Publishing, Paris, https://doi.org/10.1787/persp_glob_dev-2012-en.

Patrick, H. (2017). Asian Correspondent. Retrieved January 19, 2018, from Kuala Lumpur crowned the most expat-friendly city in Asia: https://asiancorrespondent.com/2017/11/kuala-lumpurcrowned-expat-friendly-city asia/\#BURKOStcpKHg1P2a.97

Payne, G. (2006). The SAGE Dictionary of Social Research Methods. In J. Victor (Ed.), Cohort Study (pp. 31-33). CA: Thousand Oaks.

Presse Canadienne. (2017). Quebec population rises to 8.4 million as growth rate increases. Retrieved May 1, 2018, from Montreal Gazette:http://montrealgazette.com/news/local-news/quebecpopulation-rises-to-8-4-million-as growth-rate-increases

Quebec Immigration. (2018). Quebec Immigration.org. Retrieved March 18, 2018, from Quebec Skilled Worker Program: http://www.quebecimmigration.org/

Richardson Jr., J., \& Shinjinee, S. (1996). Ethnic Conflict and Economic Development: A Policy Oriented Analysis. School of International Service, 1-11.

Spykerman, N. (2014). Expats rank Malaysia in the top 20. The Star Online. https://www.thestar.com.my/news/nation/2014/10/22/expatriates-rank-malaysia-in-top-20

Statistics Canada. (2017). 2016 Census of Population. Retrieved April 10, 2018, from Statistics Canada Catalogue: https://www12.statcan.gc.ca/census-recensement/2016/dp-pd/index-eng.cfm

The Migration Observatory. (2017). Immigration, Diversity and Social Cohesion. University of Oxford, Centre on Migration policy and Society (COMPAS), Oxford.

United Nations ESCAP. (2014). Social Cohesion, Migration Policies and The Perception of Migrant Workers in The Asia-Pacific Region. EU-Asia Dialogue (pp. 2-13). Singapore: United Nations ESCAP. 